\title{
Asia Pacific Journal of Public Health
}

\section{Physical activity tracking among Sri Lankan adults: findings from a 7-year follow-up of the Ragama Health Study}

\begin{tabular}{|c|l|}
\hline Journal: & Asia Pacific Journal of Public Health \\
\hline Manuscript ID & APJPH-20-Feb-109.R1 \\
\hline Manuscript Type: & Original Manuscript \\
\hline Keywords: & $\begin{array}{l}\text { Physical activity, Lower Middle-Income countries, Sri Lanka, Non- } \\
\text { Communicable Diseases < PUBLIC HEALTH, Population Studies < PUBLIC } \\
\text { HEALTH }\end{array}$ \\
\hline Abstract: & $\begin{array}{l}\text { Limited data are available on physical activity tracking among adults in } \\
\text { Low- and Middle-Income countries. Using a longitudinal design we } \\
\text { assessed trends and correlates of physical activity among Sri Lankan } \\
\text { adults. Individuals selected through age-stratified random sampling, } \\
\text { were screened initially in 2007 (n=2986) and re-evaluated in 2014 } \\
\text { (n=2148). On both occasions, structured interviews and clinical } \\
\text { measurements were completed. Approximately 40\% of the participants } \\
\text { engaged in recommended levels of physical activity both at baseline and } \\
\text { follow-up. One-fifth reported increased physical activity at follow-up, a } \\
\text { similar proportion reported being persistently inactive or a reduction in } \\
\text { physical activity. In the adjusted analysis, being persistently active was } \\
\text { associated with male sex, a lower educational level and income, being } \\
\text { free of any chronic disease conditions, better self-rated health, and } \\
\text { sitting time <8 hours. Our findings support public health interventions to } \\
\text { help maintain recommended physical activity levels over time, } \\
\text { particularly for subgroups at high-risk of physical inactivity. }\end{array}$ \\
\hline
\end{tabular}

\section{SCHOLARONE Manuscripts}




\title{
Title: Physical activity tracking among Sri Lankan adults: findings from a 7-year follow-up of the Ragama Health Study
}

\begin{abstract}
Limited data are available on physical activity tracking among adults in Low- and MiddleIncome countries. Using a longitudinal design we assessed trends and correlates of physical activity among Sri Lankan adults. Individuals selected through age-stratified random sampling, were screened initially in $2007(n=2986)$ and re-evaluated in $2014(n=2148)$. On both occasions, structured interviews and clinical measurements were completed. Approximately $40 \%$ of the participants engaged in recommended levels of physical activity both at baseline and follow-up. One-fifth reported increased physical activity at follow-up, a similar proportion reported being persistently inactive or a reduction in physical activity. In the adjusted analysis, being persistently active was associated with male sex, a lower educational level and income, being free of any chronic disease conditions, better self-rated health, and sitting time $<8$ hours. Our findings support public health interventions to help maintain recommended physical activity levels over time, particularly for subgroups at highrisk of physical inactivity.
\end{abstract}

What We Already Know

- Over one quarter of world's adult population do not engage in sufficient physical activity to produce health benefits

- Global trends in insufficient physically activity have not shown any notable decreases over time 
- Previous longitudinal studies of correlates of physical activity reflect mostly Upper Middle-Income countries

\section{What This Article Adds}

- Longitudinal trends and correlates of physical activity in an understudied population of a Lower Middle-Income country

- Only 39\% of the participants were able to be persistently active over a 7-year period

- Those of male gender, lower income and education, free of chronic disease, better self-rated health and lower sitting times were more successful in maintaining recommended levels of physical activity over time

\section{Introduction}

Physical inactivity is independently associated with increasing the risk for non-communicable diseases (NCDs), such as coronary heart disease, type 2 diabetes and cancer and is ranked as the fourth leading cause of death worldwide. ${ }^{1,2}$ Globally, more than a quarter of adults are estimated to be physically inactive with no signs of notable decreases in the levels of insufficient physical activity during the period $2001-2016 .{ }^{3,4}$ It is estimated that if inactivity is decreased by $10 \%-25 \%, 533,000$ to 1.3 million deaths could be prevented each year. ${ }^{2,5}$ In a worldwide attempt to enhance prevention and management of major NCDs, the World Health Organization member states have agreed to work towards a $10 \%$ relative reduction in insufficient physical activity by 2025. Sri Lanka, a Lower Middle-Income country in South $\mathrm{Asia}^{6}$, is also a part of this agreement and is working towards achieving these physical activity goals. In 2018, Physical Activity Guidelines for Sri Lankans were formulated under the direction of the National Steering Committee on Non Communicable Diseases. ${ }^{7}$ The guidelines, aligning with WHO's Global Recommendations on Physical Activity for Health ${ }^{8}$, 
Physical inactivity is a risk factor for all major NCDs that are considered a threat to global health. Yet, it is a modifiable risk factor and population level interventions to improve physical activity are an important step towards tackling the NCD epidemic, especially in Low- and Middle-Income countries such as Sri Lanka where the comparative disease burden is high. At present, most of the physical activity data within the Sri Lankan context is based on cross-sectional studies. Such data is limited in proving evidence of causal associations between physical activity and related factors. Physical activity guideline adherence estimates, based on the 2015 STEP-wise approach to non-communicable disease surveillance (STEPS) survey, indicated that $28.1 \%$ and $44.2 \%$ of the Sri Lankan adult men and women, respectively, did not meet the guidelines. ${ }^{9}$ The findings suggested that more than a quarter of Sri Lankan adults was not getting sufficient physical activity and are at risk of developing or aggravating chronic disease conditions linked to physical inactivity.

To develop effective public health interventions, understanding physical activity behaviour and its determinants is important as effective programmes can target factors known to cause inactivity. ${ }^{10}$ Longitudinal observational studies identifying factors having a strong, potentially causal, association with physical activity are under-represented in the literature with most studies using cross-sectional designs to identify correlates. ${ }^{10,11}$ Furthermore, intervention strategies that have been shown to help people initiate behaviour change have not shown to be working in the same way when it comes to behaviour maintenance. ${ }^{12}$ It should also be 
noted that previous studies on the correlates of physical activity in Low- and Middle-Income countries tend to reflect Upper Middle-Income countries ${ }^{13-15}$ where a different socioeconomic gradient may prevail compared to the countries in the Lower Middle-Income group such as Sri Lanka. Hence, to improve physical activity levels of populations in the Lower MiddleIncome counties and for formulating relevant policy, research conducted specifically focusing on people living in these counties would be helpful. The objective of this study is to describe longitudinal trends and sociodemographic correlates of physical activity guideline adherence among Sri Lankan adults.

\section{Methods \\ Participants}

The Ragama Health Study commenced in 2007 as an on-going community-based cohort study to investigate lifestyle related chronic diseases among Sri Lankan adults. The Ragama study area is situated approximately $20 \mathrm{~km}$ north of the country's capital, Colombo, and consists of an urban to suburban, multi-ethnic population. In 2007, 35-64 year old residents $(n=3012)$ of the Ragama health administrative area were selected by age-stratified random sampling from the electoral register to participate in the baseline survey. Methodological details of selecting and screening of the inception cohort are described elsewhere. ${ }^{16}$ Complete baseline records and investigation results were available for 2,986 individuals. The initial cohort was invited for a re-evaluation seven years later and 2,148 individuals participated in the follow-up assessments (response rate $72 \%$ ). 


\section{Measures}

All assessments carried out at baseline (2007) were repeated during the re-assessment (2014) and included clinical, anthropometric and biochemical measures. Participant interviews, anthropometric, and clinical assessments were conducted using standardised protocols by trained research assistants who had completed a degree in medicine. On each assessment day, 5-8 research assistants conducted the interviews and were overseen by senior medical staff. Informed written consent was obtained from all participants. Ethics approval for the study was obtained from the Ethics Review Committee of the Faculty of Medicine, University of Kelaniya, Sri Lanka (P38/09/2006).

\section{Physical activity}

At baseline and at follow-up, self-reported physical activity was assessed in a structured interview using a culturally adapted and validated Sinhalese version ${ }^{17}$ of the International Physical Activity Questionnaire - Short Form (IPAQ- SF). ${ }^{18}$ All participants were able to communicate fluently in the Sinhalese language and were asked to report the frequency and duration of vigorous physical activity (e.g. manual digging, lifting very heavy objects, etc.), moderate-intensity activity (e.g. lifting objects, slow cycling, etc.), and walking over the week immediately preceding the interview. Data gathered from IPAQ - SF was categorised into two groups based on World Health Organization Global Physical Activity Recommendations. ${ }^{8}$ A participant was categorised as 'sufficiently active' if they engaged in at least 150 minutes of moderate-intensity or 75 minutes of vigorous-intensity aerobic physical activity per week, or an equivalent combination of both. Those who did not meet these criteria were categorised as 'not sufficiently active'. To examine the longitudinal 
tracking of physical activity guideline adherence among our sample, based on these criteria, a participant was classified into one of four groups:

1. 'Persistently active' group: those who reported 'sufficient activity' both at baseline and follow-up.

2. 'Increased activity' group: those reporting sufficient activity at follow-up but not at baseline.

3. 'Reduced activity' group: those reporting sufficient activity at baseline but not at follow-up.

4. 'Persistently inactive' group: those failing to report sufficient activity both at baseline and follow-up.

\section{$\underline{\text { Sitting time }}$}

The IPAQ -SF also assessed the sitting time of respondents. Even though there is evidence linking high levels of sedentary time with detrimental health effects, currently no recommendations exist for adult sitting time thresholds. ${ }^{19}$ Sitting time was categorised into two groups: those reporting $\geq 8$ hours/day and $<8$ hours/day. A recent meta-analysis, including data from over one million participants, showed that a threshold of over 6-8 hours sitting time/day increased the risk for several major chronic diseases ${ }^{20}$, justifying the cutoffs selected in the present study.

\section{Lifestyle and sociodemographic factors}

For anthropometric measures, two recordings of both standing height and body weight of the participants were obtained using a portable stadiometer (seca $213^{\circledR}$, Seca Deutschland, Germany) and an electronic digital weighing scale (TANITA Inner Scan $50^{\circledR}$, Tanita 
Corporation America Inc, USA), respectively. Height was measured to the nearest $0.5 \mathrm{~cm}$ and weight with an accuracy of $\pm 100 \mathrm{~g}$. Body Mass Index (BMI) was calculated using the measured height and weight (weight/height ${ }^{2}$ ) and participants categorised as (i) Underweight $\left(<18.5 \mathrm{~kg} / \mathrm{m}^{2}\right)$; (ii) Normal BMI (18.5-24.9 kg/m²); (iii) Overweight (25-29.9 kg/m²); and (iv) Obese $\left(\geq 30 \mathrm{~kg} / \mathrm{m}^{2}\right) .{ }^{21}$ Waist circumference, measured at the midpoint between the lower border of the rib cage and the iliac crest using a tape measure, was categorised as high if $\geq 90$ $\mathrm{cm}$ for males or $\geq 80 \mathrm{~cm}$ for females, and normal if $<90 \mathrm{~cm}$ for males or $<80 \mathrm{~cm}$ for females as recommended for South Asians. ${ }^{22}$

All participants were asked about their smoking habits and were categorised as a current smoker or not based on their responses. Alcohol consumption was categorised as (i) Lifetime abstainer; (ii) Former drinker (people consumed alcoholic beverages but have not done so in the past 12 months; (iii) Current drinker consuming 14 units of alcohol or less per week; and (iv) Current drinker consuming more than 14 units of alcohol per week. Self-rated health was categorised into five groups by asking respondents how they felt about their general health: (i) Very good; (ii) Good; (iii) Satisfactory; (iv) Unsatisfactory; and (v) Poor. 'Unsatisfactory' and 'Poor' were collapsed into one group for data analysis purposes. A history of cardiovascular disease or diabetes was assessed by asking respondents whether a doctor has ever made a diagnosis of hypertension, hypercholesterolemia, myocardial infarction, other coronary heart disease, stroke or diabetes. If the participants responded 'Yes' to any of the conditions listed above or had any medical records that confirmed the diagnosis they were categorised as (i) Yes, or (ii) No. 


\section{Data management and statistical analysis}

All data were entered in Epi Info 7 using data entry control options for quality assurance (Centres for Disease Control and Prevention, Atlanta, GA, USA). Statistical analyses were performed using IBM SPSS version 24 (IBM SPSS Statistics for Windows, Armonk, NY: IBM Corp). Percentages and their 95\% Confidence Intervals (CI) were calculated for the four groups of participants: (a) 'Persistently active'; (b) 'Increased activity'; (c) 'Reduced activity'; and (d) 'Persistently inactive'. Chi-squared tests were used to test the unadjusted differences between the prevalence rates in each category and selected sociodemographic and health-related variables. For all statistical tests, a $p$ value of $<0.05$ was considered as significant.

Logistic regression analysis was used to assess the associations between being 'Persistently active' and sociodemographic and health-related variables. The regression model included the following explanatory variables: sex (reference group $[\mathrm{ref}]=$ male); age (ref $=55-64$ years); education (ref= passed grade 12 exit examination or higher level of education); income (ref $\geq$ US\$ 250); BMI ref = normal BMI ); waist circumference (ref = normal); current smoking $($ ref $=$ no); alcohol consumption ( $\mathrm{ref}=$ lifetime abstainers $)$; self-rated health $(\mathrm{ref}=$ very good); known history of cardiovascular disease or diabetes (ref = no); sitting time at baseline (ref $=<8$ hours). Odds ratios and their $95 \% \mathrm{CI}$ were calculated and are reported.

\section{Results}

Baseline and follow-up data were available for 2,148 respondents ( $72 \%$ follow-up response rate). In this sample, $57.6 \%$ were female, $56 \%$ were within the ages of $35-54$ years and had successfully completed Grade 10 national level school examination, or had obtained a higher 
level of educational qualification. As shown in Table 1,39.4\% of the participants were classified as 'Persistently active' at both baseline and follow-up. One in five participants (20\%) was classified to the 'Increased activity' group. A similar proportion of participants were classified as 'Reduced activity' $(21.1 \%)$ or 'Persistently inactive' (19.5\%). In the unadjusted analysis, with the exception of age and waist circumference, significant differences were observed for all other sociodemographic and health-related factors across all categories of physical activity guideline adherence $(\mathrm{p}<0.05)$.

Table 2 gives the adjusted analysis showing the overall associations with selected sociodemographic and health related variables for the 'Persistently active' category. Compared to males, females in this sample were less likely to be persistently active (Odds Radio $[\mathrm{OR}]=0.58,95 \%$ CI: $0.43-0.79)$. Age was not associated with being 'Persistently active'. Compared to those who had achieved a higher level of education, those who had no formal education or attended school only upto primary level $(\mathrm{OR}=1.57,95 \% \mathrm{CI}: 1.04$ 2.36) and those who were educated only up to grade $10(\mathrm{OR}=1.36,95 \% \mathrm{CI}: 1.03-1.81)$ were more likely to be 'Persistently active'. The odds of being 'Persistently active' were similar between those who had passed Grade 10 qualifying examination and those who had received higher educational qualifications $(\mathrm{OR}=1.24,95 \% \mathrm{CI}: 0.95-1.62)$. Participants in the highest income category (US $\$ \geq 250$ ) were least likely to be 'Persistently active' compared to those in the lower income categories, the ORs ranged from 1.85 (95\% CI: $1.27-$ 2.69) for the lowest income category of less than US\$ 50, 1.41 (95\% CI: $1.02-1.95)$ for those earning between US\$ 50 - 99, and 1.41 (95\% CI: $1.05-1.89)$ for the US\$ $100-249$ income category. 
Table 2 further illustrates that avoidance of unhealthy behaviours, like smoking or regular alcohol consumption, were not related to being 'Persistently active'. However, those who self-rated their health as 'unsatisfactory' or 'poor' were less likely to be 'Persistently active' $(\mathrm{OR}=0.57,95 \% \mathrm{CI}: 0.36-0.89)$ compared to those who rated their health to be 'very good'. Over one third of the participants in this sample had a known history of CVD or diabetes. The adjusted analysis found that participants suffering from these chronic conditions were less likely to be 'Persistently active' $(\mathrm{OR}=0.64,95 \% \mathrm{CI}$ : $0.52-0.79)$ compared to those who did not have a history of CVD or diabetes. Those reporting eight hours or more of sitting time/day were less likely to be 'Persistently active' (OR $=0.46,95 \% \mathrm{CI}: 0.32-0.66)$ compared to those who reported sitting times of $<8$ hours/day.

\section{Discussion}

This study is the first to report on the longitudinal trends of physical activity guideline adherence among Sri Lankan adults. The key findings were that being persistently active over time was independently associated with being male, having lower education/income, better self-rated health, and being free of chronic disease conditions such as cardiovascular disease or diabetes. While large-scale international population prevalence studies have been published recently ${ }^{3}$, they tend to report only cross-sectional observational data rather than for groups that change their physical activity over time. Our study is important because this adds to the under-reported literature on the factors associated with maintaining physical activity over several years as well as for a poorly studied population in a Lower Middle-Income country. 
This study confirmed that males are more active than females and that males are overrepresented in the 'Persistently active' group. This reflects robust findings in the literature ${ }^{10}$ and, in the current case, may be due to occupational and leisure patterns as well as cultural expectations and opportunities. However, the observed associations showing that lower education and income are associated with higher levels of physical activity are contrary to some other studies. For example, in a review of occupational variables and physical activity by Kirk and Rhodes ${ }^{23}$, white-collar/professionals showed the highest leisure time physical activity compared to blue-collar workers. However, other reviews suggest that such trends are less conclusive. ${ }^{10}$ Moreover, the review by Kirk and Rhodes was predominantly of studies from high-income Western counties. The findings related to education and income observed in this study can be partly explained by the type of occupations those with low educational levels may be engaged in, whereas those with higher educational levels are more likely to find better paid jobs that are less labour intensive and physically less demanding (usually in an office environment that is largely sedentary); those with low educational qualifications tend to be employed in occupations requiring manual labour that generally pays lower wages. When the analysis was extended, an association was also observed between income and sitting time with those in higher income categories significantly more likely to be sitting for $\geq 8$ hours/day $(\mathrm{p}<0.001)$.

In this study, there was an association between measures of adiposity and physical activity among adults (Table 1). This is not a surprising finding, although previously such consistent links have been shown mostly in cross-sectional studies. ${ }^{24}$ Moreover, the direction of association, if any, was not known, as it is plausible to have 'reverse causality' operating whereby adiposity may be a 'cause' of inactivity, an outcome, or both. A related finding is 
that those with chronic conditions, such as diabetes, were less likely to remain physically active. These results suggest that, despite the benefits of physical activity, chronic conditions and higher BMI could act as barriers to physical activity. This requires further study into the beliefs and motivation of people with such conditions and how they see the role of physical activity. $^{25}$

While it is common to see reports of higher self-rated health by those who are physically active $^{26}$, other at-risk health behaviours, such as smoking and regular alcohol consumption, were unrelated to physical activity maintenance. However, those with longer sitting times were less likely to be in the 'Persistently active' group. While there is some debate about the association between time spent in moderate-to-vigorous physical activity and sedentary time, it is plausible to have a cluster of 'poor' health behaviours, including high sedentary time and low physical activity. ${ }^{27}$

In future follow-up of this population the use of accelerometers to improve the validity of moderate and vigorous intensity physical activity estimates will be helpful. These devices are not commonly used for studies in South Asia and including such measures will help to create more reliable data for the region. More research should be undertaken in the region to understand demographic and sociocultural variables that could help population-wide improvements in physical activity levels as systematic differences exist between countries and cultures in the region. ${ }^{28}$ 


\section{Strengths and limitations}

There have been no previous community cohort follow-up studies, with relatively large samples sizes tracking physical activity, reported from Lower Middle-Income countries. This is the first such prospective follow-up study reporting changes in physical activity over time. Other strengths of this study include the high response rate at follow up and separate assessment of walking and sedentary behaviour using a validated tool. The main limitation of the study is the use of the IPAQ - SF, which is a self-reported physical activity tool. Physical activity data collected using wearable devices, for example accelerometers, may be the ideal but due to high costs we could not use them in this study. We have not adjusted for any over reporting that would have resulted particularly by the use of the IPAQ ${ }^{3}$ as it is known to over report in capturing physical activity data. It should also be noted that an individual's ability to perform physical activity at the fullest potential may be affected by a recent major health event like a myocardial infarction and not capturing this information could be considered as a limitation in this study.

\section{Conclusions}

The present study adds to the literature on the factors associated with participation in physical activity in two important ways. First, a Lower Middle-Income country is studied, and these are generally under-represented. Second, to better understand what might be associated with participation, we analysed data for those who have been successful in maintaining recommended levels of physical activity over a 7-year period. Results show that being persistently active seems to be associated with male sex, a lower educational level and income, being free of chronic disease conditions like CVD and diabetes, better self-rated health, and lower levels of sedentary behaviour. 


\section{References}

1. Kohl HW, 3rd, Craig CL, Lambert EV, et al. for Lancet Physical Activity Series Working Group. The pandemic of physical inactivity: global action for public health. Lancet. 2012;380(9838):294-305.

2. Lee IM, Shiroma EJ, Lobelo F, et al. for Lancet Physical Activity Series Working Group. Effect of physical inactivity on major non-communicable diseases worldwide: an analysis of burden of disease and life expectancy. Lancet. 2012;380(9838):219-29.

3. Guthold R, Stevens GA, Riley LM, Bull FC. Worldwide trends in insufficient physical activity from 2001 to 2016: a pooled analysis of 358 population-based surveys with 1. 9 million participants. Lancet Glob Health. 2018;6(10):e1077-e86.

4. World Health Organization. Global Health Observatory (GHO) data. Prevalence of insufficient physical activity.

https:/www.who.int/gho/ncd/risk_factors/physical_activity_text/en/. Accessed August 18, 2020.

5. World Health Organization. The global action plan on physical activity 2018-2030. https://www.who.int/ncds/prevention/physical-activity/global-action-plan-2018-2030/en/. Accessed August 18, 2020.

6. The World Bank. Sri Lanka Overview 2019. https://www.worldbank.org/en/country/srilanka/overview. Acccessed January 16, 2020. 7. Institute of Sports \& Exercise Medicine. Ministry of Sports. Sri Lanka. Physical Activity and sedentary behaviour Guidelines for Sri Lanka - 2018.

http://www.health.gov.lk/moh_final/english/public/elfinder/files/publications/publicNotices/ GeneralNotice/2017/Physical\%20Activity\%20Guidelines\%20for\%20Sri\%20Lankans.pdf. Accessed January 15, 2020. 
8. World Health Organization. Global recommendations on physical activity for health Report No.: 9241599979. https://www.who.int/dietphysicalactivity/global-PA-recs-2010.pdf; January $15,2020$.

9. Ministry of Health, Nutrition and Indigenous Medicine, Sri Lanka and World Health Organization. Noncommunicable disease risk factor survey in Sri Lanka 2015. https://www.who.int/ncds/surveillance/steps/STEPS-report-2015-Sri-Lanka.pdf. Accessed Auguest 18, 2020.

10. Bauman AE, Reis RS, Sallis JF, et al. for Lancet Physical Activity Series Working Group. Correlates of physical activity: why are some people physically active and others not? Lancet. 2012;380(9838):258-71.

11. Bauman AE, Sallis JF, Dzewaltowski DA, Owen N. Toward a better understanding of the influences on physical activity: the role of determinants, correlates, causal variables, mediators, moderators, and confounders. Am J Prev Med. 2002;23(2):5-14.

12. Müller-Riemenschneider F, Reinhold T, Nocon M, Willich SN. Long-term effectiveness of interventions promoting physical activity: a systematic review. Prev Med. 2008;47(4):354-68.

13. Bauman A, Ma G, Cuevas F, et al. Cross-national comparisons of socioeconomic differences in the prevalence of leisure-time and occupational physical activity, and active commuting in six Asia-Pacific countries. J Epidemiol Community Health. 2011;65(1):35-43. 14. Churangsarit S, Chongsuvivatwong V. Spatial and social factors associated with transportation and recreational physical activity among adults in Hat Yai City, Songkhla, Thailand. J Phys Act Health. 2011;8(6):758-65.

15. Ding D, Sallis JF, Hovell MF, et al. Physical activity and sedentary behaviours among rural adults in Suixi, China: a cross-sectional study. Int J Behav Nutr Phys Act. 2011;8(1):37. 
16. Pinidiyapathirage MJ, Kasturiratne A, Ranawaka U, et al. The burden of diabetes mellitus and impaired fasting glucose in an urban population of Sri Lanka. Diabetic Med. $2013 ; 30(3): 326-32$.

17. Arambepola C. Abdominal obesity and its association with selected risk factors of coronary heart disease in an adult population in the district of Colombo. Thesis (MD in Community Medicine). Postgraduate Institute of Medicine, University of Colombo, Colombo. 2004.

18. IPAQ Data Management Group. International Physical Activity Questionnaire. 2002. http://www.Ipaq.Ki.Se. Accessed August 18, 2020.

19. Ainsworth B, Rivie 're F, Florez-PregoneroLeitzmann A. Measurement of Sedentary Behaviour in Population Studies. In: Leitzmann MF, Jochem C, Schmid D, eds. Sedentary Behaviour Epidemiology. Springer; 2017.

20. Patterson R, McNamara E, Tainio M, et al. Sedentary behaviour and risk of all-cause, cardiovascular and cancer mortality, and incident type 2 diabetes: a systematic review and dose response meta-analysis. Eur J Epidemiol. 2018;33(9):811-29.

21. World Health Organization. Obesity: preventing and managing the global epidemic. World Health Organization; 2000. Report No.: 9241208945. https://www.who.int/nutrition/publications/obesity/WHO TRS 894/en/; Accessed January 15,2020 .

22. World Health Organization. Waist circumference and waist-hip ratio: report of a WHO expert consultation, Geneva.; 2008.

https://www.who.int/nutrition/publications/obesity/WHO_report_waistcircumference_and_w aisthip_ratio/en/; Accessed January 11, 2020. 
23. Kirk MA, Rhodes RE. Occupation correlates of adults' participation in leisure-time physical activity: a systematic review. Am J Prev Med. 2011;40(4):476-85.

24. Hemmingsson E, Ekelund U. Is the association between physical activity and body mass index obesity dependent? Int J Obes. 2007;31(4):663.

25. Ekkekakis P, Vazou S, Bixby W, Georgiadis E. The mysterious case of the public health guideline that is (almost) entirely ignored: call for a research agenda on the causes of the extreme avoidance of physical activity in obesity. Obes Rev. 2016;17(4):313-29.

26. Choi J, Lee M, Lee J-k, Kang D, Choi J-Y. Correlates associated with participation in physical activity among adults: a systematic review of reviews and update. BMC Public Health. 2017;17(1):356.

27. Dempsey PC, Owen N, Biddle SJ, Dunstan DW. Managing sedentary behavior to reduce the risk of diabetes and cardiovascular disease. Curr Diab Rep. 2014;14(9):522.

28. Khoo S, Morris T. Physical activity and obesity research in the Asia-Pacific: a review. Asia Pac J Public Health. 2012;24(3):435-49. 
Table 1. Prevalence of different categories of physical activity guideline adherence, sociodemographic and health-related factors at baseline

\begin{tabular}{|c|c|c|c|c|c|}
\hline & Total & $\begin{array}{c}\text { Persistently } \\
\text { active }^{\mathrm{a}}\end{array}$ & $\begin{array}{l}\text { Increased } \\
\text { activity }^{b}\end{array}$ & $\begin{array}{r}\text { Reduced } \\
\text { activity }^{\mathbf{c}} \\
\end{array}$ & $\begin{array}{c}\text { Persistently } \\
\text { inactive }^{\mathrm{d}}\end{array}$ \\
\hline & $n(\%)$ & \multicolumn{4}{|c|}{$\%(95 \% C I)$} \\
\hline Total & 2148 & $39.4(37.4-41.5)$ & $20.0(18.3-21.7)$ & $21.1(19.4-22.9)$ & $19.5(17.8-21.2)$ \\
\hline \multicolumn{6}{|l|}{ Gender } \\
\hline Male & $910(42.4)$ & $44.9(41.7-48.2)$ & $17.0(14.7-19.6)$ & $20.1(17.6-22.8)$ & $17.9(15.5-20.5)$ \\
\hline Female & $1238(57.6)$ & $35.4(32.8-38.1)$ & $22.1(19.9-24.5)$ & $21.9(19.7-24.3)$ & $20.6(18.4-22.9)$ \\
\hline & & \multicolumn{4}{|c|}{$p<0.001$} \\
\hline \multicolumn{6}{|l|}{ Age (years) } \\
\hline $35-44$ & $366(17.0)$ & $43.2(38.2-48.3)$ & $22.7(18.6-27.2)$ & $17.8(14.1-21.9)$ & $16.4(12.9-20.5)$ \\
\hline $45-54$ & $832(38.8)$ & $40.9(37.6-44.2)$ & $19.7(17.1-22.5)$ & $20.7(18.0-23.5)$ & $18.8(16.2-21.5)$ \\
\hline \multirow[t]{2}{*}{$55-64$} & $950(44.2)$ & $36.7(33.7-39.8)$ & $19.2(16.7-21.8)$ & $22.8(20.3-25.6)$ & $21.3(18.7-24.0)$ \\
\hline & & \multicolumn{4}{|c|}{$p=0.06$} \\
\hline \multicolumn{6}{|l|}{ Education } \\
\hline Primary to no formal education & $161(7.5)$ & $45.3(37.8-53.1)$ & $16.1(11.1-22.4)$ & $27.3(20.9-34.6)$ & $11.2(7.0-16.8)$ \\
\hline Grade 6-9 & $793(36.9)$ & $42.6(39.2-46.1)$ & $19.0(16.4-21.9)$ & $21.3(18.6-24.3)$ & $17.0(14.5-19.8)$ \\
\hline Passed grade 10 qualifying exam & $761(35.4)$ & $39.2(35.7-42.7)$ & $21.0(18.2-24.0)$ & $19.6(16.9-22.5)$ & $20.2(17.5-23.2)$ \\
\hline \multirow[t]{2}{*}{ Passed grade 12 exit exam or higher level } & $433(20.2)$ & $31.9(27.6-36.4)$ & $21.2(17.6-25.3)$ & $21.2(17.6-25.3)$ & $25.6(21.7-29.9)$ \\
\hline & & \multicolumn{4}{|c|}{$p<0.001$} \\
\hline \multicolumn{6}{|l|}{ Monthly family income (in US\$) } \\
\hline$<50$ & $313(14.6)$ & $45.4(39.9-50.9)$ & $12.5(9.1-16.5)$ & $23.6(19.2-28.6)$ & $18.5(14.5-23.1)$ \\
\hline $50-99$ & $646(30.1)$ & $39.9(36.2-43.8)$ & $20.9(17.9-24.2)$ & $22.0(18.9-25.3)$ & $17.7(14.4-20.2)$ \\
\hline $100-249$ & $863(40.2)$ & $40.4(37.2-43.7)$ & $20.2(17.6-22.9)$ & $19.6(17.0-22.3)$ & $19.8(17.3-22.6)$ \\
\hline \multirow[t]{2}{*}{$=>250$} & $326(15.1)$ & $30.1(25.3-35.2)$ & $24.8(20.4-29.8)$ & $21.2(17.0-25.9)$ & $23.9(19.5-28.8)$ \\
\hline & & \multicolumn{4}{|c|}{$p<0.001$} \\
\hline
\end{tabular}




\begin{tabular}{|c|c|c|c|c|c|}
\hline & Total & $\begin{array}{l}\text { Persistently } \\
\text { active }^{\mathrm{a}}\end{array}$ & $\begin{array}{l}\text { Increased } \\
\text { activity }^{\mathbf{b}}\end{array}$ & $\begin{array}{r}\text { Reduced } \\
\text { activity }^{c}\end{array}$ & $\begin{array}{c}\text { Persistently } \\
\text { inactive }^{d}\end{array}$ \\
\hline & $n(\%)$ & \multicolumn{4}{|c|}{$\%(95 \% \mathrm{CI})$} \\
\hline \multicolumn{6}{|l|}{ Body Mass Index $\left(\mathrm{kg} / \mathrm{m}^{2}\right)$} \\
\hline Underweight $(<18.5)$ & $150(7.0)$ & $40.7(33.0-48.7)$ & $22.7(16.5-29.9)$ & $20.7(14.8-27.7)$ & $16.0(10.8-22.5)$ \\
\hline Normal (18.5-24.9) & $1127(52.5)$ & $42.4(39.5-45.3)$ & $18.5(16.4-20.9)$ & $20.2(18.0-22.7)$ & $18.8(16.6-21.2)$ \\
\hline Overweight (25-29.9) & $687(32.0)$ & $35.1(31.6-38.7)$ & $20.2(17.4-23.4)$ & $24.0(20.9-27.3)$ & $20.7(17.8-23.8)$ \\
\hline Obese $(\geq 30)$ & $184(8.6)$ & $36.4(29.7-43.6)$ & $25.5(19.6-32.2)$ & $16.3(11.5-22.2)$ & $21.7(16.2-28.1)$ \\
\hline & & \multicolumn{4}{|c|}{$p=0.032$} \\
\hline \multicolumn{6}{|l|}{ Waist Circumference (cm) } \\
\hline Normal (males $<90 ;$ females $<80$ ) & $1021(47.5)$ & $39.5(36.5-42.5)$ & $20.9(18.5-23.4)$ & $21.2(18.7-23.7)$ & $18.5(16.2-21.0)$ \\
\hline High $($ males $\geq 90 ;$ females $\geq 80)$ & $1127(52.5)$ & $39.4(36.6-42.3)$ & $19.2(16.9-21.5)$ & $21.1(18.8-23.6)$ & $20.3(18.0-22.7)$ \\
\hline & & \multicolumn{4}{|c|}{$p>0.05$} \\
\hline \multicolumn{6}{|l|}{ Current smoking } \\
\hline No & $1834(85.4)$ & $38.1(35.9-40.3)$ & $20.8(19.0-22.7)$ & $21.2(19.4-23.1)$ & $20.0(18.2-21.8)$ \\
\hline Yes & $314(14.6)$ & $47.5(42.0-53.0)$ & $15.3(11.6-19.6)$ & $20.7(16.5-25.4)$ & $16.6(12.8-21.0)$ \\
\hline & & \multicolumn{4}{|c|}{$p=0.009$} \\
\hline \multicolumn{6}{|l|}{ Alcohol consumption } \\
\hline Lifetime abstainers & $1353(66.5)$ & $37.6(35.1-40.2)$ & $21.1(19.0-23.3)$ & $20.8(18.7-23.0)$ & $20.5(18.5-22.8)$ \\
\hline Former drinkers & $180(6.9)$ & $40.6(33.6-47.9)$ & $17.2(12.2-23.3)$ & $26.1(20.1-32.9)$ & $16.1(11.3-22.0)$ \\
\hline $\begin{array}{l}\text { Current drinker } \leq 14 \text { units of alcohol per } \\
\text { week }\end{array}$ & $554(24.9)$ & $42.4(38.3-46.7)$ & $19.3(16.1-22.9)$ & $19.5(16.3-23.0)$ & $18.8(15.6-22.3)$ \\
\hline $\begin{array}{l}\text { Current drinkers }>14 \text { units of alcohol } \\
\text { per week }\end{array}$ & $61(1.7)$ & $49.2(36.1-62.3)$ & $9.8(3.7-20.2)$ & $29.5(18.5-42.6)$ & $11.5(4.7-22.2)$ \\
\hline & & \multicolumn{4}{|c|}{$p>0.04$} \\
\hline \multicolumn{6}{|l|}{ Self-rated health } \\
\hline Very Good & $109(5.1)$ & $49.5(40.2-58.9)$ & $20.2(13.4-28.5)$ & $15.6(9.7-23.3)$ & $14.7(8.9-22.3)$ \\
\hline Good & $931(43.3)$ & $40.8(37.7-44.0)$ & $18.8(16.4-21.4)$ & $21.1(18.5-23.8)$ & $19.3(16.9-22.0)$ \\
\hline
\end{tabular}




\begin{tabular}{|c|c|c|c|c|c|}
\hline & Total & $\begin{array}{c}\text { Persistently } \\
\text { active }^{\mathrm{a}}\end{array}$ & $\begin{array}{l}\text { Increased } \\
\text { activity }^{b}\end{array}$ & $\begin{array}{l}\text { Reduced } \\
\text { activity }^{c}\end{array}$ & $\begin{array}{c}\text { Persistently } \\
\text { inactive }^{\mathrm{d}}\end{array}$ \\
\hline & $n(\%)$ & \multicolumn{4}{|c|}{$\%(95 \% \mathrm{CI})$} \\
\hline Satisfactory & $680(31.7)$ & $41.3(37.7-45.1)$ & $19.7(16.8-22.8)$ & $20.4(17.5-23.6)$ & $18.5(15.7-21.6)$ \\
\hline \multirow[t]{2}{*}{ Unsatisfactory or poor } & $428(19.9)$ & $30.8(26.6-35.3)$ & $22.9(19.1-27.1)$ & $23.8(20.0-28.0)$ & $22.4(18.7-26.6)$ \\
\hline & & \multicolumn{4}{|c|}{$p=0.012$} \\
\hline \multicolumn{6}{|c|}{ Known history of cardiovascular disease or diabetes } \\
\hline No & $1430(66.6)$ & $44.1(41.5-46.6)$ & $19.7(17.7-21.8)$ & $20.2(18.2-22.4)$ & $16.0(14.2-18.0)$ \\
\hline \multirow[t]{2}{*}{ Yes } & $718(33.4)$ & $30.2(26.9-33.7)$ & $20.5(17.6-23.5)$ & $23.0(20.0-26.2)$ & $26.3(23.2-29.6)$ \\
\hline & & \multicolumn{4}{|c|}{$p<0.001$} \\
\hline \multicolumn{6}{|l|}{ Sitting time } \\
\hline$<8$ hours & $1965(91.5)$ & $40.9(38.7-43.1)$ & $19.2(17.5-21.0)$ & $21.6(19.9-23.5)$ & $18.3(16.7-20.1)$ \\
\hline \multirow[t]{2}{*}{$\geq 8$ hours } & $183(8.5)$ & $24.0(18.3-30.6)$ & $28.4(22.2-35.3)$ & $15.9(11.1-21.7)$ & $31.7(25.3-38.7)$ \\
\hline & & \multicolumn{4}{|c|}{$p<0.001$} \\
\hline
\end{tabular}

${ }^{a}$ To be classified as 'persistently active' a respondent had to report at least $150 \mathrm{~min}$ per week of moderate-intensity physical activity or 75 min of vigorousintensity physical activity per week, or an equivalent combination of both, at baseline and follow-up.

${ }^{\mathrm{b}}$ To be classified in the 'increased activity' group a respondent had to report at least 150 min per week of moderate-intensity physical activity or 75 min of vigorous-intensity physical activity per week, or an equivalent combination of both at follow-up but a lesser amount of activity at baseline.

' To be classified in the 'reduced activity' group a respondent had to report at least 150 min per week of moderate-intensity physical activity or 75 min of vigorous-intensity physical activity per week, or an equivalent combination of both at baseline but a lesser amount of activity at follow-up.

d To be classified 'persistently inactive' a respondent had to report less than 150 min per week of moderate-intensity physical activity or 75 min of vigorousintensity physical activity per week, or an equivalent combination of both, at baseline and follow-up. 
Table 2. Adjusted odds ratios ${ }^{\mathrm{a}}(\mathrm{OR})$ and their $95 \%$ confidence intervals $(95 \% \mathrm{CI})$ for being classified as 'Persistently active'b between 2007 and 2014 by sociodemographic and healthrelated factors.

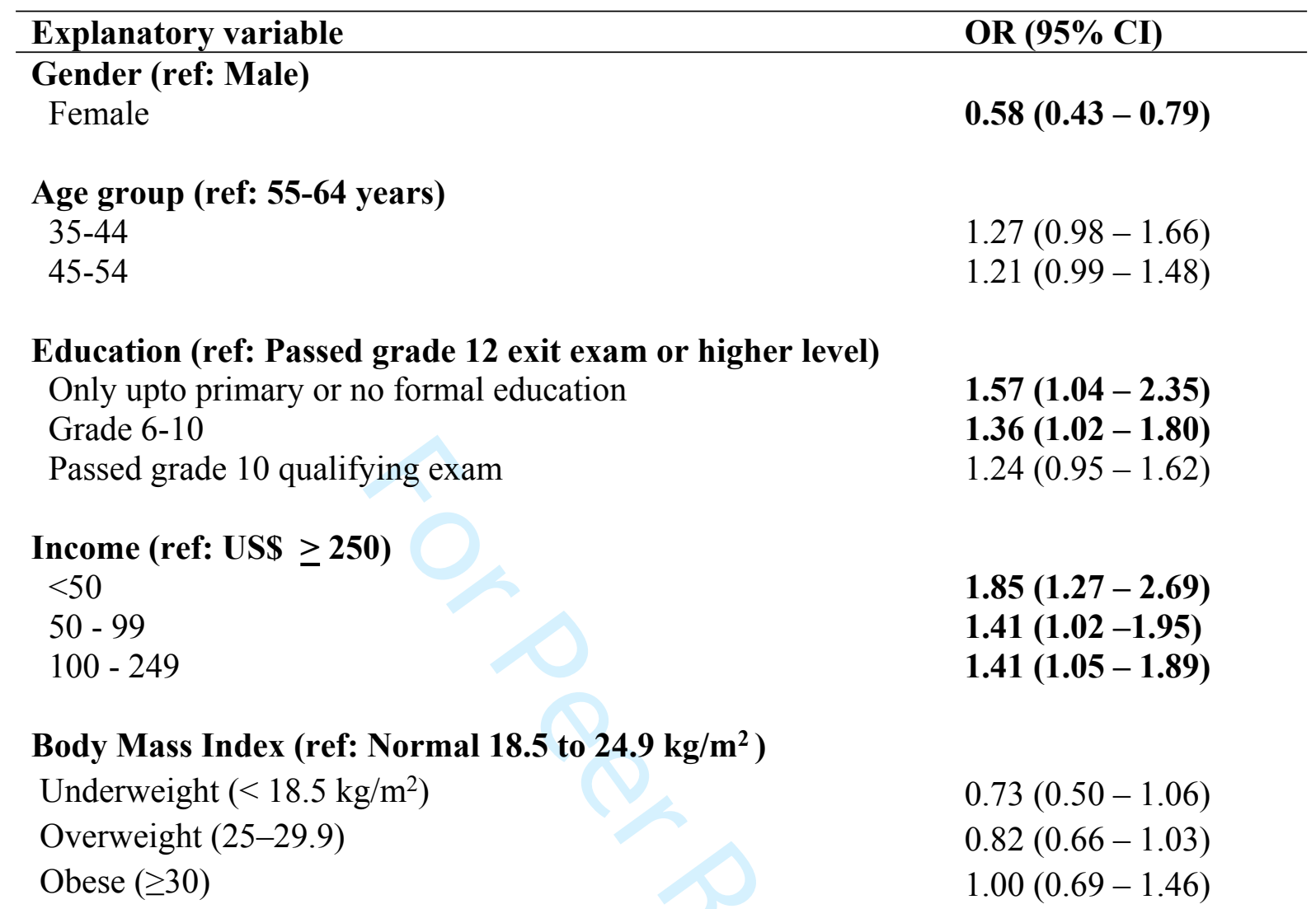

Waist Circumference (ref: normal males $<90$; females $<80 \mathrm{~cm}$ )

High (males $\geq 90$; females $\geq 80$ )

$0.94(0.74-1.20)$

Current smoking (ref: No)

Yes

$1.01(0.75-1.37)$

Alcohol consumption (ref: Lifetime abstainers)

Former drinkers

$0.82(0.57-1.19)$

Current drinkers $\leq 14$ units of alcohol per week

$0.86(0.64-1.16)$

Current drinkers $>14$ units of alcohol per week

$0.99(0.55-1.77)$

Self-rated health (ref: Very good)

Good

$0.76(0.50-1.14)$

Satisfactory

$0.80(0.52-1.21)$

Unsatisfactory or poor

$0.57(0.36-0.89)$

Known history of cardiovascular disease or diabetes (ref: No)

Yes

$0.64(0.52-0.79)$ 


\section{Sitting time at baseline (ref: $<8$ hours)}

$\geq 8$ hours

$0.46(0.32-0.66)$

a adjusted for all variables in the table.

${ }^{b}$ to be classified as persistently active a respondent had to report at least 150 min per week of moderateintensity physical activity or 75 min of vigorous-intensity physical activity per week, or an equivalent combination both, at both 2007 and 2014 . 